Open Access

\title{
Emerging health technology firms' strategies and their impact on economic and healthcare system actors: a qualitative study
}

\author{
Mathieu Beaulieu* (1) and Pascale Lehoux
}

* Correspondence: mathieu. beaulieu@umontreal.ca

Department of Health Management, Evaluation and Policy, Institute of

Public Health Research of University of Montreal (IRSPUM), P.O. Box

6128, Centre-ville Branch, Montreal,

Quebec H3C 3J7, Canada

\section{Abstract}

A growing number of announcements on new and innovative medical devices are reported each year by economic actors. However, very few new technologies are successfully acquired and adopted by healthcare actors. To examine how economic and healthcare system actors perceive entrepreneurs' strategies employed to respond to and address healthcare system actors' pressures following firm's emergence, we gathered data with 20 healthcare system and economic actors using semi-structured interviews and thematic analysis. We have determined that the acquisition and diffusion of health technologies are increasingly regulated and must respond to increasing pressures from many actors who see their agency power decline. We have found that political strategies address the pressures from institutionalization of practices and decoupling of the health system and its goals, associative strategies react to the power of key influencers such as investors and medical specialists, and mistrust of marketing actions, normative strategies respond to pressures stemming from the growing need for evidence-based data; finally, identity strategies answer to the fragmentation of a public health system and the heterogeneity of local procurement processes are approached. The results may help medical professionals, decision-makers, and evaluators to understand medical device acquisition and diffusion process better.

Keywords: Innovation in health, Legitimacy, Reputation building, Neo-institutional theory, Actors, Competitive actions, Social construction

\section{Background}

\section{Study background}

\section{Research problem}

Great advances and achievements have been made over the course of the past six decades in the field of medical technology. With the advent of personal computing in the 1980s, the Internet in the 1990s and the completion of the human genome at the turn of the twenty-first century, the number of companies developing health technology exploded (Baker and Khamsi 2012). These mostly privately developed technologies have become established in both public and private health systems because they respond to health needs expressed by populations, health professionals, and decision-makers (Donabedian 1973). However, progress and advancements have been slow in the way

(c) The Author(s). 2018 Open Access This article is distributed under the terms of the Creative Commons Attribution 4.0 International License (http://creativecommons.org/licenses/by/4.0/), which permits unrestricted use, distribution, and reproduction in any medium, provided you give appropriate credit to the original author(s) and the source, provide a link to the Creative Commons license, and indicate if changes were made. 
technologies are, on the one hand, developed and marketed and, on the other hand, evaluated and acquired (Gagnon 2014). Advances also have not kept pace with the health technology assessment (HTA) trends that have emerged in the biotech and pharmaceutical fields (Chilcott et al. 2010). Still, clinical practice increasingly relies on these technologies while an expanding number of private and public third payers require their formal assessment in the context of an acquisition process (Oortwijn and Van der Wilt 2016).

Compared to the pharmaceutical field, the field of health technologies is receiving much less attention. The vast majority of information on the subject consists of industry reports and investigating business strategic and business intentions. In addition, the question of commercializing the benefits of health research is often put forward by policymakers in their science policies; however, this notion is sometimes poorly received, often justifiably, and almost always poorly conceptualized, both from the point of view of the industrial fabric and the managers of the public healthcare system (World Health Organization 2011b). The same comparison shows a low penetration of the clinical and home environment which is caused by the difficulties in overcoming the many known barriers to adoption, which are needed from the design stage to dissemination and implementation. But while the evaluation of technologies and the study of the diffusion of innovations have given rise to an important scientific literature, few studies have so far explored the emergence of innovative health technology companies taking into account the point of view of all actors involved (Richter 2004).

\section{Importance of health technology industry}

The global medical device manufacturing industry is made up of more than 27,000 companies and employs approximately one million people (International Trade Administration 2016). It is an industry with a low level of concentration because no single firm is dominant. Thereby, it is composed of many small businesses, which usually specialize in the development of niche technologies. Large players often seek to acquire small businesses to expand their product mix or access-specific technologies or markets (Martino et al. 2012). However, in the past 5 years, a wave of consolidation has swept the industry, and the number of companies has decreased. Meanwhile, emerging markets like China and Brazil are attracting many manufacturers of medical devices (Innovation Science and Economic Development Canada 2017). In 2017, the main sectors of activity in the global health technology market were non-durable products (15\%); diagnostic devices, such as magnetic resonance imaging and tomography (27\%); prostheses, such as hearing aids and pacemakers (12\%); orthopedic products (11\%); dental products $(7 \%)$; and other medical devices (28\%) (Innovation Science and Economic Development Canada 2017). It is estimated that by 2019 , the global market for medical devices will be US $\$ 398$ billion, excluding in vitro diagnostic equipment. The USA, with a market value of US $\$ 188.9$ billion (36.3\% of the world market), is the largest and most developed market and the world's largest supplier of medical devices, with 1625 leading medical device companies worldwide. In recent years, BRIC's four markets (Brazil, Russia, India and China) have grown rapidly: in 2016, they represented a combined market of 26.2 billion US dollars. Even if, in absolute terms, its spending per capita remains low; at 10.5 billion US dollars, China is the fourth largest market in the world and should reach the second rank by the end of 2018 (International Trade Administration 2016). 


\section{Theoretical background}

Our research is grounded in the neo-institutional theory, with emphasis on social construction concepts (legitimacy seeking and reputation building), considering the institutionalization of practices, the influence of the organizational field, and the tendencies towards isomorphism. To diffuse their technology, firms must go through a process of legitimacy and reputation build-up and must influence actors, such as investors, doctors, a wide range of private and public decision-makers, and ideally catch the eye of the media. By doing so, organizations engage in sensegiving activities to attract attention through competitive actions (e.g., marketing campaigns, symbolic action, partnerships), which connote various intentions (e.g., appeal to cognitive, moral or pragmatic legitimacy, or reputation-building). Furthermore, firms respond to pressures originating from financial and regulatory bodies, health professionals, and shareholders.

\section{Market actions and social construction}

Research on competitive dynamics has shown that the total amount or level of a firm's market actions, rather than any particular type of action, is the most robust predictor of its performance (Ferrier et al. 1999). This finding can be explained by the fact that firms possess heterogeneous resources, which they can deploy in diverse types of action to create value for stakeholders. The firm market actions will inform stakeholders via press releases about its ability to create value for them because the more actions a firm takes, the more information stakeholders have, the easier it is for them to form impressions about a firm and develop a better understanding of its strategy. As a result, stakeholders are likely to become more confident about making choices to exchange resources with the firm and are also likely to evaluate it more positively (Basdeo et al. 2006).

Studies have shown that entrepreneurs use narrative information to clarify their vision and growth strategies, providing and assigning meaning to events, that is through a sensegiving process (Suchman 1995). Sensegiving is a strategic effort of social construction found particularly in emerging organizations and reflected in intensity and diversity of activities. Various sensegiving activities are also associated with higher levels of funding for financial partners (Petkova et al. 2013). In accordance with work from Suchman (1995), we observed in a previous study that startups go through three social construction patterns consisting of gaining, maintaining, and regaining legitimacy, reputation, and status to support their expansion (Author name removed 2017). These empirical results suggested that the marketing and symbolic actions, doubled with recourse to prominent actors, were particularly pronounced with the health tech startups when compared to the non-health firm. Furthermore, health tech startups were the only firms heavily searching for cognitive and pragmatic legitimacy, thus relying on cognition rather than actors' self-interest or moral judgments. The health tech startups were also under far more content and control-related pressures originating from a markedly higher number of actors who differed in type and numbers.

Previous empirical results on firms' emergence showed a decrease over time in prominence, with recourse to institutional intermediaries and prestigious actors (Author name removed 2017). Likewise, the prominence is replaced by cognitive and pragmatic legitimacy by increasing actions pertaining to regulatory approvals, scientific 
presentations, and conformation to shareholder demands. Another difference encountered with the health tech startups is in the type and the multiplicity of actors, creating the need to deal with somewhat conflicting demands. Following the initial gain legitimacy phase, the few informative signals on the product or the company are replaced by symbolic actions, such as prestigious board nominations, prices, or new brand identities. Ultimately, a decrease in prominence is replaced by an increase in cognitive and pragmatic legitimacy. These results are particularly relevant to fulfill this paper's goal since they could push research participants to reflect on how health technology entrepreneurs employ strategies to address pressures originating from healthcare and financial system actors, as perceived through their perspective.

Institutionalization of practices, isomorphism, and organizational fields

An institution may be a structure, a practice, a relationship, and an object, which becomes "taken for granted" and that is supported by normative systems and cognitive understanding that gives meaning to social exchanges, allowing the social order to self-replicate (Meyer and Rowan 1977; Wooten and Hoffman 2008). Institutions can also be considered as models of sequenced interactions supported by specific control mechanisms. In this respect, institutions are the product of specific measures taken to be reproduced, modified, and destroyed (Jepperson 1991). Institutions are inter-subjective, thus recognized by others, and cognitive because the interactions depend on the cognitive capacities of the actors (Fligstein 2001). In our project, we define the health system as an institution because it has shared rules and meanings that define social relationships and guide the interactions and behaviors of actors.

Another important concept to the theory is isomorphism, which is a powerful institutional force that pushes players to become more similar over time. In the long-term, organizational actors who make rational decisions build an environment that limits their ability to change more in subsequent years. The first to adopt organizational innovations are often motivated by the desire to improve performance but when an innovation diffuse, a threshold is reached beyond which the innovator legitimizes its adoption rather than improving its performance (Meyer and Rowan 1977). Finally, the concept of organizational field, central in the new institutional theory, is defined by a set of organizations that constitute a recognized domain of life (Dimaggio and Powell 1983). These fields include powerful institutional forces that cause their members to become like each other over time. Thus, the limits of the fields, the identity of its members, and the interactions between the members are delimited and maintained by one or more shared institutional logics (Greenwood and Suddaby 2006).

\section{Strategic responses available to organizations}

Organizations are not passive recipients and do not react blindly to institutional pressures (Oliver 1991). Thus, five different strategic responses are available to organizations: acquiescence, compromise, avoidance, defiance, and manipulation. Furthermore, five factors can predict firms' responses: cause (the reason why the firms are pressured); constituents (who is exerting the pressures); content (which pressures); control (how these pressures are exerted); and context (what is the environmental context). As introduced earlier, our previous results suggest that the factors 
predicting organizational response to institutional pressures have different patterns depending on the firm type and lifecycle (startups vs. established firms) (Author name removed 2017). Pressures related to content conformity, originating from health and financial regulatory bodies, are mainly encountered with the health startups and are maintained continuously towards the standardization of their practices. Contrary to pressures towards content conformity, control-related pressures towards normalization are constant throughout all three phases for the three health startups as it mirrored health professionals' involvement and expectations throughout product development and commercialization. Finally, reputation building using the prominence lever piggybacks another actor's reputation to build oneself up.

Our study is about the entrepreneurs' strategies employed to respond to and address healthcare system actors' pressures wherever they are related to content, control, or context. These strategies materialize under the firms' competitive actions as well as their social construction efforts over the institutionalization of actors' practices, their tendency to become similar with time, and the interactions and contextual elements within the organizational field. These strategies are derived and adapted from the empirical research of Lawrence and Suddaby (2006), who have observed several distinct sets of practices through which actors have engaged in actions that have resulted in the creation, maintenance, or disrupting institutions. They can be political at an important level (lobbies and associations) as well as at a low level (direct channel of communication between company representatives and key actors). They can also be associative, by recruiting key influencers, investing in medical education, and increasing representative visits, or normative, by increasing communications through formal channels and push regulatory submissions. Finally, identity strategies are employed by constructing formal agreements between firms and healthcare system actors and involving firms to participate in the elaboration of a unified and cohesive acquisition process.

\section{Research objectives}

Because new health technologies are popping up every year but only a few of them are acquired and diffused, we aim to help medical professionals, decision-makers, and evaluators to understand medical device acquisition and diffusion. Thereby, the objective of this paper is to examine how economic and healthcare system actors perceive entrepreneurs' strategies employed to respond to and address healthcare system actors' pressures, following firm's emergence. More specifically, our qualitative study examines the views and practices of a range of actors who actively fund, evaluate, or participate in the acquisition process of such devices. Study aim is also to examine what are the strategies adopted by health tech entrepreneurs to address pressures and influence from healthcare and economic actors. We also investigate how economic and health system actors influence the introduction of institutional changes in response to competitive actions and the meaning given to them by entrepreneurs. Interview participants were asked to comment on the results of previous research in which we followed startup health tech companies and analyzed their market actions and corresponding intentions through press releases, media coverage and stock market valuation (Beaulieu and Lehoux 2017). 


\section{Results and discussion \\ Results}

In the iterative analysis process, three themes were predominant as expected: The first theme being the institutionalization of relations and exchanges, followed by the isomorphism process, the contextual elements, and the interactions between actors within the organizational field. A fourth, unexpected emerging theme took shape in the form of decoupling between health systems and actors' goals. The four themes and sub-themes related to neo-institutional theory are summarized in Table 1 . We present our findings with the help of participants' quotes that are representative in terms of both relevancy and frequency.

\section{Institutionalization of practices}

A new set of rules The difference between formal and informal relationships was often raised. Specifically, the participants stressed the importance and past ubiquity of informal relationships between industry representatives and other stakeholders. It seems that these informal relationships, from friendships to multiple exchanges of documented information, facilitated assessment and promoted a more rapid adoption of the technology. The context of bureaucratization and current budget restriction therefore complicated, codified, and institutionalized exchanges between actors. When we addressed the subject of interactions between health professionals and industry representatives, "the official and unofficial" (HP-11) ways to interact were discussed. Reflecting on shifting context, most participants alluded to the political and organizational changes affecting Canadian healthcare system for several years. There seems to be consensus that a new set of rules has emerged, one that differs greatly from the previous system: "But now the Minister does not longer allow this practice." (HP-11).

Most participants agreed that the currently prevailing rigid practices give way to nostalgia towards interactions as they stood a few years back:

Before we had only to modulate the tender to meet the color of the car that we wanted but now it is no longer possible ... Here in the hospital, it is a case. I must admit I have had remarkable success, but the political aspect still can be an obstacle, because we often change our managing director. We position the department towards the acquisition of recent technologies that scientifically and technologically appeal to new principles. It is difficult to defend, and the Ministry never wants to

Table 1 Summary of the themes and sub-themes

\begin{tabular}{ll}
\hline Themes & Related sub-themes \\
\hline A. Institutionalization of practices & A1. A new set of rules \\
B. Isomorphism & B1. An increasing number of actors \\
& B2. The need of quality data \\
& B3. Different acquisition processes \\
C. Organizational field & C2. Changing perceptions \\
D. Decoupling of health system and actors' goals & D1. A misalignment of goals \\
& D2. A complex bureaucratic hierarchy \\
\hline
\end{tabular}


invest money. So, we must finance ourselves by creating a financing structure which, with the help of the hospital, bypasses the Ministry. (MD-04)

\section{An increasing number of actors}

One participant involved in the evaluation process said "The technologies are increasingly complex. So [manufacturers] tend to make simpler messages because it can be difficult to explain something very complex in a short message to an increasing number of different actors." (HA-15). Regarding the need for evidence, most participants pointed out that companies should further emphasize the incremental benefit harbored by their technology because it is often the basis on which the decision to acquire and adopt their technology is based. Participants who were not medical specialists noticed that efforts were increasingly targeted to medical specialists, while less informative information (and therefore, less technical features) was provided to the other actors involved in the acquisition process.

\section{Isomorphism}

Power of key influencers Even in the financial community, analysts can connect sales to the scientific perception of the product. Medical specialists were also very sensitive to the fact that the product used in other health centers can facilitate the acquisition process in their favor: "If you have 50 hospitals competing, and your company is struggling to provide, it means that you offer a real service. Or you are not asking for a fair price." (HI-19).

On the other hand, evaluators tend to ignore everything that is not evidence, even considering marketing approaches as negative:

I do not want to be condescending with individuals who are involved in marketing, sales ... but that's another conception. Anything that tends to promote, by elements that are not necessarily evidence, we are not looking at that. (HA-17)

On the contrary, a participant involved in technology investment stressed that actions with marketing intentions content do not deplete but rather enrich technology informative content, considering the context of media exposure that characterizes our era:

I'm not sure why there is a perception that it is 'impoverished'. If anything, I think it is on the rise, especially with Twitter and omni-channels. This is a major channel for our health startups to raise awareness to the public and key influencers. (HI-20)

Similarly, four participants raised the awareness of the impact of their technological acquisitions as a tool for prominence-based marketing:

When we acquire a technology, we also consider our image. For if we acquire a technology we know very well that company representatives will walk through the province and boast that we have acquired this technology. We have an important responsibility following our analysis because we also consider the impact on other actors in the health system. (HP-13) 
Among the partnership agreements, changes in portfolio, regulatory issues, and symbolic actions, the latter seem to influence some actors, especially those in the medical field and the financial world:

In symbolic actions, there are opinion leaders and advisory committees. It plays its role. If this is a person who is known, who is connected to the sector, who has an impact on what he says and focuses on research and all that, it has an impact on society, for sure. Whoever has the most opinion leaders is better. (HI-18)

The tradition of using opinion leaders is a longstanding practice in the biopharmaceutical world and is increasingly used in the field of health technology. Furthermore, the numerous signals emanating from a company on the appointment of prestigious directors or the creation of an advisory committee may in turn further influence investors. In fact, one participant involved in financing pointed out that the publication and use of testimonies by patients or key influencers now constitutes a perfectly valid and effective strategy to reach and influence decision-makers.

Two actors stand out in that organizational field. These are the first investors who have virtually the power of life and death over the product and medical specialist who will be at the center of the technology acquisition decision: "If it is the physician who is primarily the user he will surely be the main decision maker." (HP-11).

Despite the cumbersome process and the number of actors involved in the decisions, doctors (particularly medical specialists) are still at the center of hospital technology acquisition decisions or are consulted by evaluation units. Moreover, tech companies increasingly need to recruit key opinion leaders. It is on the reputation and curriculum of the latter that companies will build part of their social construction. Key opinion leaders are also called upon to be ambassadors of technology in their organizations. Another example was evoked by a healthcare professional:

I always remember that the number one argument when a doctor prescribed something was, has my boss prescribed it before? So, the game is to find a reference person to present the new technology to you and I feel that this is the most successful thing to do to sell a technology. (HP-13)

The need for quality data Among the repertoire of competitive actions, some themes stood out, such as the information provided on the clinical studies and the reported sales. Sending evidence-based signals is what is the most anticipated, used, and appraised by health actors. Paradoxically, it was found that a lack of data often afflicts health technologies, when compared for example to pharmaceuticals: "There is a lack of data in the industry side as they come at a time when they want to introduce their product and emerge into the field, but there is no data to support them." (HA-17).

The role of organizations that establish guidelines was raised several times: "For us the guidelines are the truth of the Lord and that changes everything. When guidelines change within a year, the world changes accordingly." (HP-13). All of them agree that a 
change in guidelines quickly leads to changes in practice, and thus in technology choices. And although medical specialists are at the heart of technological decisions, some participants noted a sporadic lack of rigor when evaluating the data provided by tech companies. For an evaluator:

Sometimes I question the quality of the data provided to us or even of the guidelines. It is sometimes a good thing to critically appraise this material. And are doctors able to assess the actual effectiveness of the technology or the quality of some publications? We would like physicians to have the reflex of assessing the relevance of technology, to question, to adopt a critical perspective. (HA-17)

It is to say that some question physicians' support and endorsement of a specific product; it goes back to the importance of demonstrating the incremental benefit.

Participants were asked if regulatory agencies take too much space in the process of adoption and diffusion of innovation. All participants said they have a crucial and capital importance. Similarly, the inclusion of technology in an approval process gives it an extra veneer of legitimacy: "Having to go for approval to Health Canada shows the seriousness of the approach." (HP-12).

Different acquisition processes Within health technology assessment units, some heterogeneity was encountered: some hospitals have highly structured and solicited units; others do not have this technological choice and rely on the administration that, most of the time, relies on the opinion of doctors. As already mentioned, budget problems appear to undermine these groups, and participants highlighted the disproportionate efforts put into research and sales, versus efforts on evaluation and demonstration of the incremental benefit:

For sure we do not have half a quarter of the budgets of these organizations [pharmaceuticals, biotechs and medical devices companies]. If there were a portion used to demonstrate the comparative effectiveness ... there could be a lot of interesting evaluation research. (HA-16)

This is because there are lots of administrative steps. There are even requests that we make again year after year ... For example, our bronchoscopes are dangerous now ... It often happens that for monetary reasons we do not get what we want. (MD-09)

On the one side, we have investors wondering how to attract market attention, how to gather favorable financing conditions, and product marketing. On the other side, evaluation experts wonder why some of these efforts cannot be diverted to technology assessment. It is easy to find situations where innovative products, after having completed several investment cycles, were being refused in the face of a misjudged market or a failure to demonstrate of the incremental benefit of the innovation against the current product:

We could interact, help them even before the product is launched on the market, because now we are in a customer-supplier relationship and cannot promote the product, because we are missing the data to know if it works. (HA-17) 
In the same vein, an investor emphasized the cumbersome bureaucratic system, which in his opinion slows the growth of technologies: "Bureaucratic systems in Quebec are far too heavy. It is a real barrier to innovation. Several tech entrepreneurs went straight to the United States because of that." (HI-19).

\section{Organizational field}

A low fragmented system and challenging market cycles Another issue was raised by HTA unit's participants, in the form of the low fragmentation of publicly funded health systems such as the Canadian health system. In the Canadian context, most acquisitions in health technology ultimately must receive government approval, which can be a major obstacle to the sale of a technology when such bodies direct almost all acquisitions where there can be negative evaluations or extensive administrative lengths: "There is a link between government support and timing of acquisition." (HA-16).

A second issue raised by stakeholders, but primarily by investors, pertained to the financing of innovative technologies. Market cycles seem to be the major challenge and a major determinant for the valuation of an innovation and of a company. In addition, the type of investor, whether involved early or late in the technology development cycle, may also explain these variations. Indeed, early investors must have access to larger and more sustained funds that the investor who joins later funding rounds when the technology is practically already sold. It also appears that access to financing would be inversely proportional to the required budget:

If a project needs 20 million and other project needs 300 million and both have the same market potential I will choose the 20 million project. Because if I'm wrong just five to 10 million is not too serious, but if I'm wrong by $+/-50$ million on a 300 million project so now it's up to 150 million. (HI-18)

Finally, given that investors are involved in both bio-pharmaceutical and health technologies, they stressed that the rules were different between a drug and a medical device.

Changing perceptions A participant repeatedly stressed that the success of the development of medical technology was based on triad financing, management skills of the leadership team, and evidence-based data. Risk sharing between investors, entrepreneurs, and actors from the health community was also often raised: "As for investors we ask a lot of questions about the type of financial model or business plan developed to be able to go to marketing and then remain a player in the market." (HI-20).

When interactions with representatives were discussed, health system actors were divided between medical specialists and other health professionals, evaluators, and administrators. The first seem to consider industry representatives as a reliable source of information and do not hesitate to consider these relations when they appraise the technology:

It is clear that the barrier to entry is to find the right person in the healthcare system. But who is the right person? This is the one who can see the need for this technology. This is someone who is not too deep inside the administrative spheres but who can figure it out. (MD-01). 
On the other hand, the second group of actors seemed relatively wary of the actions and informal content originating from the industry: "But sometimes the representatives are creating a need" (HP-11). This dichotomization was well explained by a healthcare professional:

What I've seen is that the technology had been approved in other provinces but not in Quebec. So, the representative used the old technique of creation of an advisory committee. The purpose of the advisory committee was to present the technology, supported by dramatic testimonies. While I was eating my very expensive dinner, I figured out the outcome of the meeting. It was to sign a petition to the government and claimed that our group wants an access to the technology. With our group, it did not work, but with the specialists it worked. (HP-14)

So, it turns out that a large part of product development concerns the quality of the actors or the interaction of these actors with each other:

We can meet representatives of big multinationals, but they are not the key players in the acquisition or development of technology. We will usually reach the scientific delegate of the company ... Recently, a large company approached us, but their product didn't work. I showed them the reason and they left downhearted. And you know what? Finally, they saved millions because the product would not have worked. (MD-05)

\section{Decoupling of health system and actors' goals}

A misalignment of goals Per some participants of all backgrounds, the acquisition process is dysfunctional. The main bottleneck in the diffusion of health innovation seems to be in the acquisition process. Health centers usually have two types of budget in the form of replacement budgets and development budgets: "Once there is the word "development, it is denied" (HP-11). A new technology that is not intended to replace existing equipment but instead meet new needs must demonstrate very strong relevance and usefulness. A keyword constantly heard during the interviews was "need": "You have to know what's needed: the first question we ask ourselves." (HP-12). This requires that the need be clearly identified by purchasers and that it coincides perfectly with the technological offer: "Usually people who manage the budgets ask us to define the real needs." (HP-12). In fact, health stakeholders want to match not only the needs and technological offer, but also the transaction cost of acquiring the technology:

Which practices or interventions will the new technology displace? It was found that to move an activity of a group of professionals to another led to more than one refusal to acquire a technology. For example, to enable, through technology, nurses to make acts once reserved for doctors. (HA-17)

To this end, the element that came up most often was the misalignment of what is offered on the technology side, the needs identified by the health network, technological gain as identified by experts, and ultimately the small amount and quality of information available during product evaluation. The simple lack of time and resources 
to evaluate technologies could also explain some of the slowness and complexity of the acquisition process:

The other difficulty is that the administration believes very little in terms of improving patient care. Administrators do not take the patient's health into account because they rely only on their annual budget. For example, the reduction of hospitalizations or readmissions is not recorded. All because these things are difficult to evaluate. (MD-03)

The implication of the introduction of technology can also affect some actors who are not necessarily directly targeted. Thus, the introduction of technology can shuffle the cards and redefine the new rules of the game: "The technologies can also direct a flow of patients from one specialty to another. There may therefore be some resistance to change." (HA-17). Such resistance to change may be much greater than the simple fear towards newness found in the target users of the new technology: "There are technologies that are probably profitable, are beneficial for society but which do not diffuse because professionals in question deflect and say this is not how we work." (HA-17).

Other actors such as the foundation of a hospital can intervene and support the choice of technology:

The Foundation is often considered a solution ... The problem is that it is often a reason given by the hospital administration to avoid financing the development. But the existence of the Foundation cannot be the solution to the funding of all development projects. (MD-10).

But the main challenge in terms of technology acquisition is still a budgetary one. For an investor: "One [...] challenge is commercial. That even if the clinical studies are successful at the scientific level ... Even though we have this study and had the money to do it people must still be prepared to use and pay for it." (HI-18). There seems to be a lack of communication between companies and their investors, and purchasers who are the health actors:

The benefit is measured in the facility but is established on the patient's path outside the hospital. Inside the hospital, it prevents the patient coming to the hospital. Technologies are always expensive. The only way to somewhat recover this investment is for care to be provided by people who are cheaper. Or it is done outside this expensive environment. (HA-17)

A complex bureaucratic hierarchy Another recurring theme was the organizational field of technological innovations in health where there are too many actors:

Clearly. It is endless. The regulation budget is probably 10 times the real purchasing budget. There's an infinite number of stakeholders in a hospital ... as here there are probably 10 decision-making levels before it happens. People have new positions in newly recreated decision-making bodies that were not even there when the decisions were taken. The latter cast doubt on decisions that have been taken before. It'll cost more down the line. (MD-02) 
One technology evaluator had a different opinion and even suggested the inclusion of additional actors:

I do not think there's too many players. Even sometimes we would like to include more people, for example we have talked for years about getting patients involved in the decision-making process. (HA-15)

Another evaluator said many times that not only were there too many participants in the process, but that the main problem was in the divergence and heterogeneity of goals found in these individual actors:

Looking at all these groups before a decision is taken ... it seems that there is no direct channel of information. It seems that everyone has their agenda and there is no correspondence between the agendas; thus, innovation has a tough time to go through the process of acquisition; it would have to sensitize everyone ... At the end, we end up aligning ... but it takes a long time. (HA-16)

\section{Strategies and associated pressures}

Our study focused on entrepreneurs' strategies employed to respond to and address healthcare system actors' pressures, as perceived by the economic and healthcare actors. In the light of our primary findings, our initial conceptualization was enriched by including the presence of decoupling of goals and of external actors. We then re-examined the data under the concept of institutional work as strategies engaged by the entrepreneurs, from which notes and important quotes are found in Tables 2, 3, 4, and 5. We found that pressures pushing towards and institutionalization of practices and of decoupling of health system and actor's goals are addressed by political strategies; power of key influencers such as investors and medical specialists, as well as mistrust towards marketing actions, are addressed with associative strategies; pressures originating from the increasing need for evidence-based data are addressed with normative strategies; finally, the low fragmentation of a public healthcare system and the heterogeneity of local acquisition processes are addressed with identity strategies. These results shape the process by which health technology companies respond to real needs, as defined by the mission of health systems.

\section{Discussion}

Our results emphasize that acquisition and diffusion of health technologies processes are increasingly regulated and must meet growing pressures from an increasing number of actors who inversely see their agency power reduced. On the one hand, local health professionals still have some agency leeway within the acquisition process and the resulting flexibility may explain the relative success and perpetuation of current practices (Kitchener 2002). Yet, on the other hand, this freedom is increasingly challenged by pressures originating from actors within and outside the organizational field, leading to an institutionalization (formalization) of exchanges and practices. In accordance to the neo-institutional theory and data gathered from interviews, over time, the solidification and codification of exchanges 
Table 2 Political strategies and associated pressures

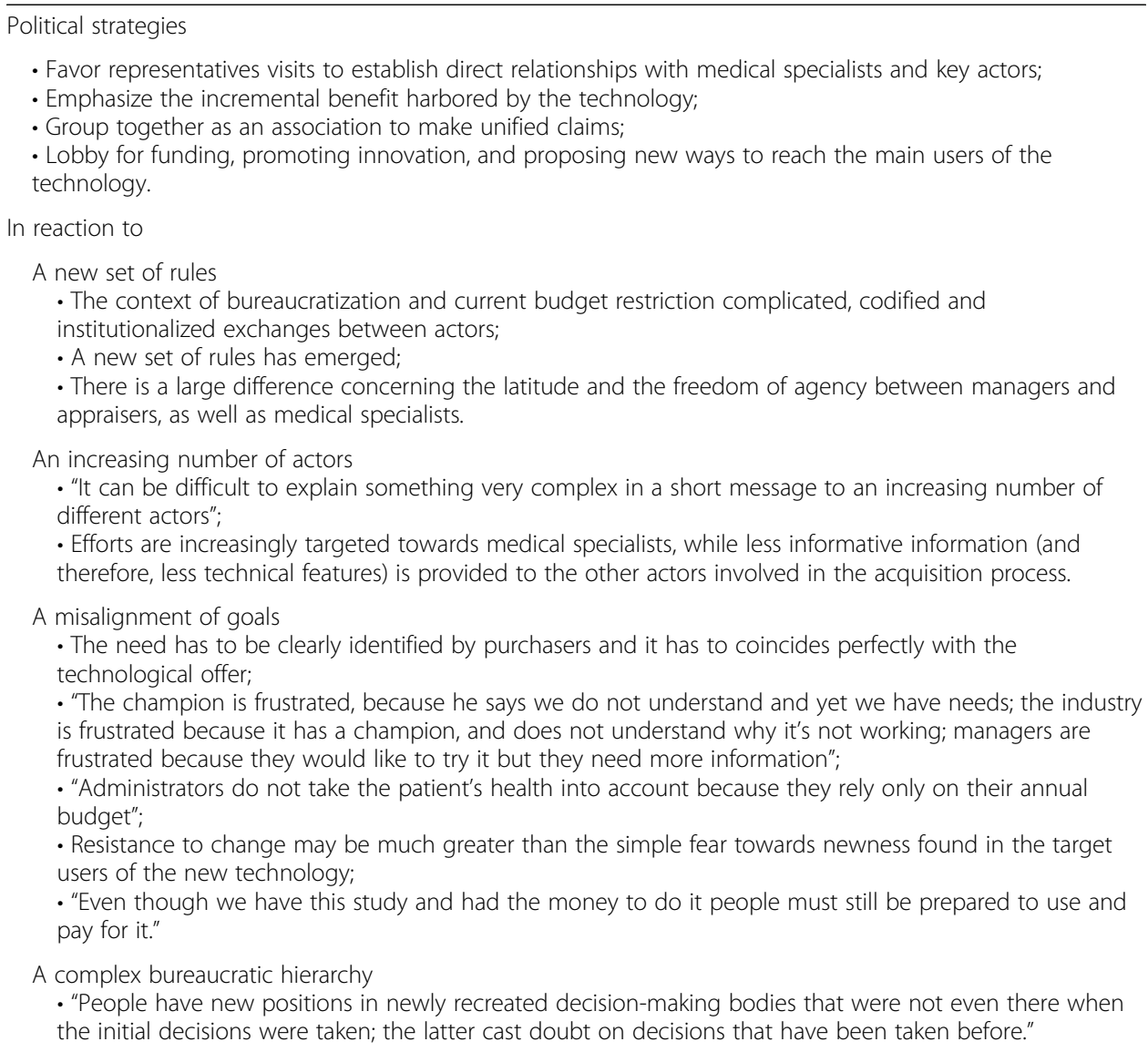

lead economic actors, health system, and firms to become similar within their respective group. In the context of our study, the political, associative, normative, or identity strategies employed by the entrepreneurs to penetrate the healthcare system institution are in fact a mix of actions aimed at maintaining (when the rules in place favor the firm) and disrupting institutions. Thus, actors often have

Table 3 Associative strategies and associated pressures

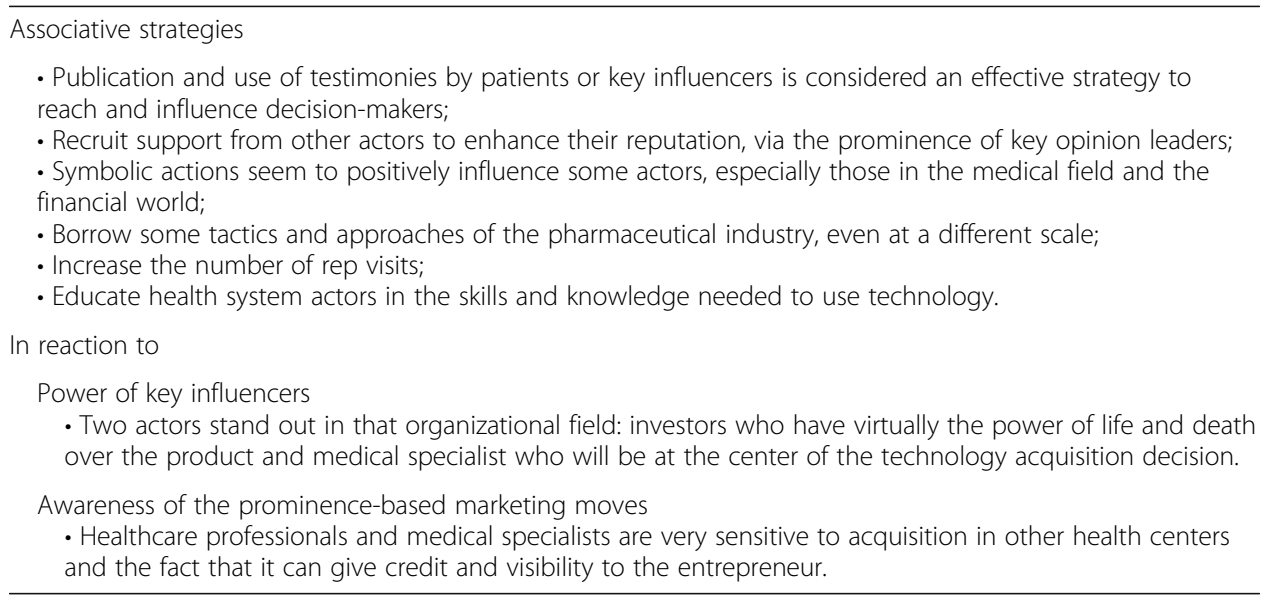


Table 4 Normative strategies and associated pressures

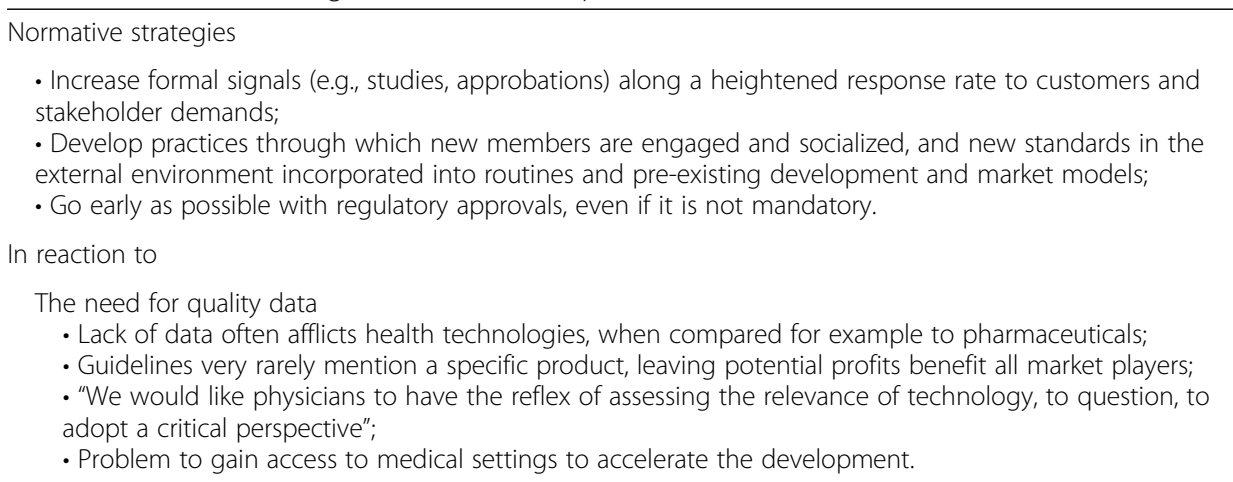

differing agendas, from which undergo different institutional pressures, all of which may constitute obstacles to the adoption of a technology.

\section{Political strategies}

Our findings suggest that the old fashion way, where doctors hoping to acquire medical devices had their wish granted by the hospital administration is now long gone. The increase in the number of actors leads not only to an increase in the gap between healthcare system and actors' goals, but also to a formalization of rules and a growing reduction in both firms and health actors' agency power (Oliver 1991). Content and control-related institutional pressures are numerous: growing demand for high-quality information from health policymakers, financial pressures on health centers with constantly shrinking budgets; purchasers and users of these technologies themselves face pressure from the input of other health professionals which can feel threatened by the introduction of a new technology (Lehoux et al. 2005). Another layer of complexity arises when one scrutinizes other

Table 5 Identity strategies and associated pressures

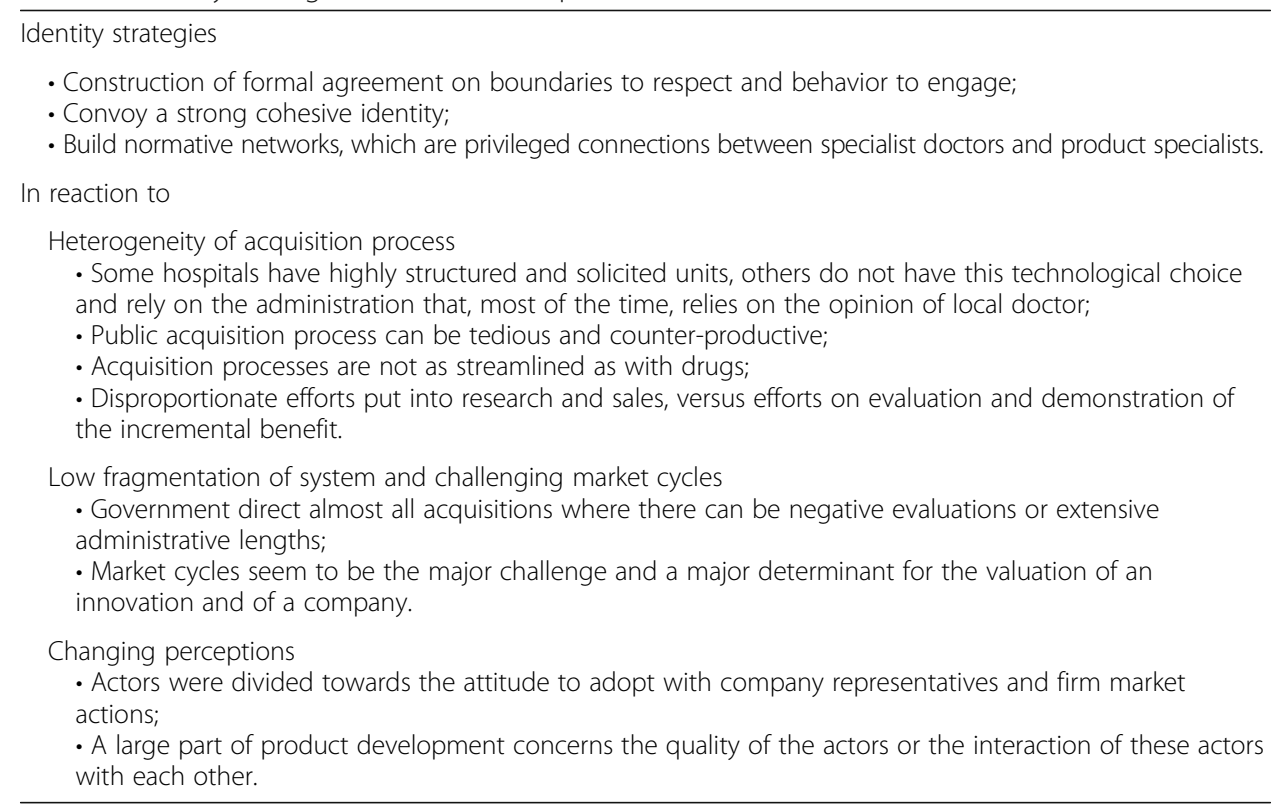


players that are not considered initially, such as philanthropic foundations and public pressure, which can intervene and encourage the purchase of technologies. In the end, pressures are reflected in the heterogeneity of actors' responsibilities and roles, and albeit different and sometimes conflicting between groups, they shape relations within the organizational field (McCarthy and Mayer 1977).

Decision-makers often do not consider the patient's trajectory as a whole (including going back into a community setting) but only under the perspective of their jurisdiction (Oliver and Sorenson 2009). These conflicting pressures contribute to the decoupling of the health centers' mission (an increase in patients and population health) and decision-makers' goals (within their respective financial budget) (Meyer and Rowan 1977). This means that hospitals can undergo structural and mission changes without necessarily changing their practice and decision frameworks (Hallet and Ventresca 2006; Meyer and Rowan 1977). It turns out that technologies that could be highly beneficial to the general population are denied due to the narrowness of their evaluation framework (e.g., limited perspective and temporal horizon) (Canadian Agency for Drugs and Technologies in Health 2006). Healthcare cost constraints, demands to improve health outcomes, a greater emphasis on quality, and the introduction of new technologies and procedures available for clinical use all are driving healthcare payers to reassess how they make decisions about which tests and services to cover and under what conditions they will reimburse them. Health insurance plans have emphasized evidence-based coverage decision-making to determine which technologies and services are appropriate to cover (Lehoux et al. 2005). However, the evidence needed to make informed coverage decisions is lacking for many innovative health technologies. Similarly, a study found that cost-saving innovations were encouraged by patients paying their own bills because they had high-deductible coverage or were uninsured (Havighurst 2008).

Political strategies (Table 3) are set in motion to react to the new set of rules put in place in the health system, amplified by the budgetary restrictions and the increasing number of actors to be addressed. They are also a response to the actor's misalignment of goals, to the complex bureaucratic hierarchy, and to the dysfunction of the innovation ecosystem. In this set of strategies, the reactions of the entrepreneurs are to try as much as possible to favor direct relationships with medical specialists through representatives or directly from their executives. A political game is set up, bypassing the secondary actors and directly accessing the actors who have the most weight, which is most of the time the medical specialist.

\section{Associative strategies}

Among participants' responses, two common strategies emerged: approach health decision-makers using mainly the lever reputation coupled with prominence (recourse to opinion leaders) and release marketing-oriented signals of variable usefulness. In return, these strategies carry content that influences how the firm is perceived and how the technology will fit in the acquisition process. These findings corroborate results from Rindova et al. (2005), which suggest that the extent to which an organization is widely recognized in its organizational field strongly influences the economic value of its reputation. An extremely interesting result is the awareness of healthcare actors of the potential impact of the acquisition of health technologies at their facility. Some participants knew that every acquisition can 
enhance a firm's prominence although the firm's claims may not be entirely supported, knowing that the green light may have been given due to pressures from a small but influential group within the organization. This awareness could be a preventive reaction to a logic of social influence as defined by Kuran and Sunstein (1999), e.g., to avoid organizations to gain disproportionate amount of attention and support on the basis of nonspecific impressions.

Associative strategies (Table 3) are responses to the power of key influencers and the actors' awareness of prominence-based marketing moves. From the perspective of our two groups of actors, mimetism is an important form of institutional work in the development of the medical technology industry. It is observed when firms imitate the conventions of the pharmaceutical industry and evoke practices accepted by health system actors such as regular representatives' visits and contribution (albeit in a smaller scale) to continuing medical education (Steinman and Baron 2007). This strategy is opposed to health technology entrepreneurs who traditionally used to rely mainly on technical demonstration and whose technologies did not require human and financial capital of the same order of magnitude as today (Hines et al. 2010). In addition, this approach involves putting emphasis on educating health system actors in the skills and knowledge needed to use technology. As heard many times during the interviews, a key strategy employed by entrepreneurs to educate large number of actors is to recruit support from other actors to enhance their reputation, via the prominence of key opinion leaders. This approach, also imported from pharmaceuticals, favors the firm visibility and positive image by providing access to key information such as case studies and practical applications to a set of actors who otherwise would have already formed an opinion of the product on incomplete information (Kerger et al. 2016).

\section{Normative strategies}

Another interesting finding related to the firm's emergence process is that although the use of opinion leaders is becoming more popular and mimics increasingly the pharmaceutical industry practices, participants denoted that over the product lifecycle an increase in cognitive content is proportionate to the use of pragmatic legitimacy. That is, an increase in formal signals (e.g., studies, approbations) goes along a heightened response rate to customers and stakeholder demands (Suchman 1995). While this tendency to increase information-rich signals is observed throughout settings, it is clear that the use of evidence-based data is what is the most anticipated, has the greatest impact, and what is often still lacking with decision-makers (Barnett et al. 2011).

Despite inextricable bureaucracy and an increasing number of actors involved in the choice of a health technology, all stakeholders agreed that the two main actors influencing the diffusion of technology are still investors and doctors (mainly medical specialists). So, despite a constantly evolving and expanding organizational field, the collective rationality in the medical device sector binds traditional actors to an established innovative industrial logic, perpetuating institutional practices (Scott 2001). Even considering the crucial role of doctors, some participants had a few doubts about the ability of the latter to assess health technologies, in settings where assessment is not performed by solid evaluation units. Thus, studies with 
complex designs and economic models require indeed to be assessed by experts in the field to be appropriately evaluated (Grutters et al. 2011). The growing involvement of health technology assessments may challenge traditional medical influence in some organizations, but the extent of their field-level impact is still to be studied (Hoffman 2001).

Normative strategies (Table 4) respond to content-related pressures, whether it is from health system actors which demands evidence-based data and government which demands regulatory approvals and organized, public acquisition processes. To integrate the healthcare system institution and respond to these normative pressures, firms increase their formal signals (e.g., studies, approbations) along a heightened response rate to customers and stakeholder demands. However, level of reception will depend on the quality of interactions and channels previously created and enabled between actors and entrepreneurs. Furthermore, entrepreneurs need to develop practices through which new members are engaged and socialized, and new standards in the external environment incorporated into routines and pre-existing development and market models (Bergsland et al. 2014).

\section{Identity strategies}

Although their similar backgrounds and mission would have pressured them to become similar, an important observation was the low degree of normative cohesion between institutions (Suchman 1995). Certain institutions go through a straight pipeline for technology assessment, while other health centers do not even have an evaluation unit within their walls. However, with similar backgrounds and training, all players in the healthcare system agree that decisions are made after an inconstant and cumbersome bureaucratic process. This variability in normative frameworks may represent either a significant barrier or an accelerator in the diffusion of technologies (Schulman et al. 2009). Firms may indeed have much less resistance to being compliant in settings where the acquisition process is straightforward (Oliver 1991).

Our findings indicated that health tech startups are perceived as organizations that are flexible, rapidly adaptable, and more closely aligned with their client needs. Volatility, dependence on the success of a small number of products, a small product portfolio, and an emerging credibility were, however, identified by participants as negative contextual assets. The organizational field response to a firm's new device is inherently shaped up by the former's preconceptions and anticipations. Indeed, contextual components may drive the extent to which actors will exert pressures on the firm's proposition. Subsequently, each side adjusts its strategies and finds a common ground, leading health clients to consider acquiring the device. The larger context may also be important. For example, the current fragmentation of the Canadian healthcare system leads the manufacturer to adapt not only to the various provincial healthcare systems, but also to each health center. While several technologies are acquired through group purchases, the incremental benefit of the technology should usually be assessed within each center. Moreover, public healthcare systems can be strongly influenced by federal, provincial, and local political decisions, which can all add another layer of contextual complexity (World Health Organization 2011a). 
Identity strategies (Table 5) are formed to address the heterogeneity of acquisition processes, the peculiarities of a publicly funded and low-fragmented healthcare system, the challenging market cycles, and the attitudes of different healthcare actors towards firm's market actions. The entrepreneurs' strategies as perceived by the field actors are to construct identities by forming professional associations to establish intraprofessional agreement on boundaries to respect and behavior to engage (Greenwood et al. 2002). These associations could allow the diffusion of shared meanings and lead to the elaboration of strategies defining a common identity (Galvin 2002). Another strategy addressing the low level of normative cohesion involves building normative networks, which are privileged connections between specialist doctors and product specialists through which practices are normally sanctioned, such as routine presence and visits of company representative (Zipkin and Steinman 2005).

\section{Strengths and limitations}

This semi-structured interviews approach is, as with all research, not without limitations. The volume of data (nearly $18 \mathrm{~h}$ of interviews), the focus of the conceptual model, together with the article length limitation, impacted on the depth of analysis that was possible within the available resources. However, after having collected data with 15 participants, we encountered similar instances repeatedly and became empirically confident that our themes were saturated, meaning additional interviews analyzed brought decreasing marginal contributions to the findings. Our criteria for determining saturation were a combination of the empirical limits of the data and the integration and the density of the theoretical model and themes (Glaser and Strauss 1967). Our results are based upon a sample of sufficient size and participant diversity to provide a reasonable reflection of views of healthcare system and economic actors in a publicly funded healthcare system. Furthermore, although all participants were gravitating around the Quebec and Ontario healthcare systems, most of them had international experience and involvement (investors, medical specialists). Indeed, some medical specialists were not part of the universal coverage system and held a private practice. Altogether, without losing sight of the Canadian environment, most of the results could also be transferable to structurally different healthcare systems since most medical devices firms sell or license their products internationally.

Our multiple, iterative 20 interviews using a thematic analysis method offered a credible mean of investigating complex social units consisting of multiple themes of importance in understanding the emergence of health tech firms (Yin 2014). Besides, our results are highly consistent since a standardized questionnaire and a unique conceptual model were used to gather and analyze the data. Anchored in real-life situations, our results represent a rich and holistic account of the startup emergence process (Kvale 2007). In addition, we ensured methodological rigor using a written protocol to minimize investigator bias and reflexive thematic analysis which paid attention to all themes and to outliers. Still, the questionnaire was based on previous research results, and therefore, some questions (namely questions 7,8 , and 9) may appear judgmental or closed but they nonetheless reflect 
our previous conclusions. Incidentally, these questions brought a broad range of reactions which were revealed to be among the most informative and contrasted answers received.

Furthermore, summarizing the case studies under a general conceptual model and theory may be proven difficult. However, these difficulties arose from the properties of the process studied, and not the research method (Flyvberg 2006). Additionally, using different organization theories may have brought different conclusions, but under a set of alternative assumptions. We carefully considered the scope of the project, the emphasis on the creation and solidification of relations between actors, and the social construction of the innovative firm. After much deliberation, the neo-institutional theory emerged as the best set of explanations on which to base our model.

\section{Policy implications}

We interviewed 20 participants, including medical specialists, health professionals, evaluators, and investors, about their perception of entrepreneurs' strategies employed to respond to and address healthcare system actors' pressures. The results contributed to refine our understanding of the processes using four themes related to the neo-institutional theory: the institutionalization of practices and exchanges, the isomorphic process taking places between groups of actors, the role of the organizational field represented by the quality of interactions and contextual elements, and the decoupling between health centers' mission and decision-makers' goals. The findings were defined by the process by which health technology firms address actual technology needs defined by the healthcare system mission, via recourse to political, associative, normative, or identity strategies addressing the requirements, demands, and pressures originating from the healthcare system.

For the decision-makers, the results can be used to develop and enrich acquisition and evaluation policies and guidelines that will improve access to medical technologies that are safe, effective, and of high quality. These policies can be implemented at four levels: in support of companies during research and development phases, with regulatory bodies, technological evaluation units, and groups involved in global or local procurement processes. The nature of decision-making involves a process that is often contested, and this is particularly true for health technology policy making. In recognition of the field in which these technologies are developed and the often-divergent interests of a range of stakeholders, compliance with certain principles should be particularly applied. It is the development of policies based on the basic values of the health system, a largely consultative and transparent process, the participation of all stakeholders, evidence-based decisions, and ultimately, the ascertainment that technology responds to real health needs and is used efficiently and effectively.

Collaborative mechanisms could also be identified to allow a group of potential users to benefit from the expertise and field experience of another group that is already using the technology. Moreover, with the rationing of health budgets, decision-makers involved in the acquisition process are increasingly faced with the need to further detail acquisitions to justify the financial resources used. The managers involved should therefore be able to support the acquisition process and 
ensure that the maximum amount of information is available and that this information is valid, reliable, and relevant. The application of revised policies could also promote interprofessional collaboration and development of partnerships with private enterprise.

\section{Conclusions}

This research focused on economic and healthcare systems actors. Further research would be needed to understand the last piece of the process that is the logic behind the moves and intentions of innovators. Although participants were all gravitating towards the Canadian healthcare system, our results could be used to further examine structurally different healthcare systems. Our results reinforce the notion that actors within an organizational field (e.g., medical devices) may respond differently to internal and external pressures whether by managing multiple and incompatible simultaneous goals, and by formalizing their practices and exchanges. Indeed, understanding the elements contributing to the emergence, success, and sustainability of innovative tech companies may contribute ultimately to increasing the ratio of successful innovative product commercialization over new product announcements. The findings and conclusions from this work provide relevant information that could be integrated into a wider program of research on the behavior of the distinct types of actor within the medical device industry, healthcare system, investors groups, and policymakers.

\section{Methods}

The research consists of semi-structured interview inquiries that allowed the researcher to tailor the questions to the interviewee and to the interview context. The sampling strategy was purposive, seeking to ensure a good external and internal diversification. The sample was determined by the richness of the experience each participant could share. In detail, the participants are medical specialists labeled as participant MD 1-10: 3 cardiologists, 3 intensivists, 1 biochemist, 1 gastroenterologist, 1 intensivist pediatrician and 1 plastic surgeon; 4 health professionals involved in health technology acquisition (HP 11-14): 2 hospital pharmacists, 1 bachelor nurse and 1 biomedical engineer; 3 members of health technology assessment units (HT 15-17); and 3 investment fund partners specialized in health innovations (HI 18-20).

\section{Data collection}

Sampling base for medical specialists and healthcare professionals originated from tertiary, teaching hospitals affiliated with the University of Montreal: the University of Montreal Health Centre (CHUM), which is one of two major healthcare networks in the city of Montreal and one of the largest hospitals in Canada; the Montreal Heart Institute, which is a specialty hospital dedicated to the development of cardiology; the Hôpital du Sacré-Cœur de Montréal, one of the largest teaching hospitals affiliated with the University of Montreal and one of the largest hospitals in Quebec; and the Centre hospitalier universitaire Sainte-Justine (CHU Sainte-Justine), which is a pediatric and obstetric university health center. Intensive and cardiology care departments were primarily targeted because their users are traditionally known to depend 
heavily on the latest health technologies. Other medical specialists were selected based on their interest in the project due to their involvement in these departments. Within the teaching hospitals, 52 invitations were sent and 10 responded. Members of health technology assessment units were also sent invitations on the basis of their collaboration with the Institut national d'excellence en santé et services sociaux (INESSS), which is collaborating with 11 university hospital centers in Québec to support them in the acquisition decision-making process. Among the 11 invitations sent, three responded favorably. Finally, the sampling base for the health tech investment funds partners consisted of all pertinent fund partners and managers having their offices in Montreal, Quebec, or Toronto, Ontario. Thereby, 3 investors responded favorably among the 12 invitations sent.

Prior to data collection, a series of themes was developed to guide the research. We designed a 1 h-length interview questionnaire, composed of 11 questions, which can be found in the Appendix. The questionnaire was divided in three parts, with questions on the economic and publicly funded healthcare system actors' response and impressions on (1) key issues affecting the financing, development, evaluation, or use of innovation in health; (2) firms' competitive actions and requirements, needs, and pressures originating from healthcare actors; and (3) attitude towards innovation and media coverage.

We primarily gathered data through semi-structured interviews that were conducted between April and December 2015. The flexibility of the semi-structured interviews allowed researchers to probe for a deeper understanding while maintaining high standards of reporting and data analysis (Galletta 2013). Special attention was given to various professional settings that would be conducive to creating an appropriate environment for data collection. Each interview lasted 50-60 min, and respondents were free to develop the conversation within each topic area. At the end of the interview, a summary was given to check if the interviewer understood the respondent's answers correctly. Participants then had the opportunity to add or change relevant information. After every interview, the questionnaire was reviewed and annotated if the interviews revealed essential information and concepts that were not yet included. All interviews were digitally recorded and transcribed verbatim within 7 days. Data were collected until no new concepts emerged, and theoretical saturation was reached, which happened before having reached 20 interviews (Glaser and Strauss 1967).

\section{Analysis}

To put in context these strategies and associated responses, we use an explanatory model integrating the concepts of influence, communication, institutional work, and pressures between actors in the health technologies' organizational field (Fig. 1). This model depicts the process of development, acquisition, and diffusion of health technologies in public and private health systems. Throughout this process, emerging businesses seeking to commercialize these technologies must build themselves socially within their organizational field, towards economic and healthcare system actors. The model posits that the firm reacts to events depending on its type (well established vs. startup) and its current social construction "pattern," defined by gaining, maintaining, or regaining its social position. By doing so, it gives sense to its activities with the levers 


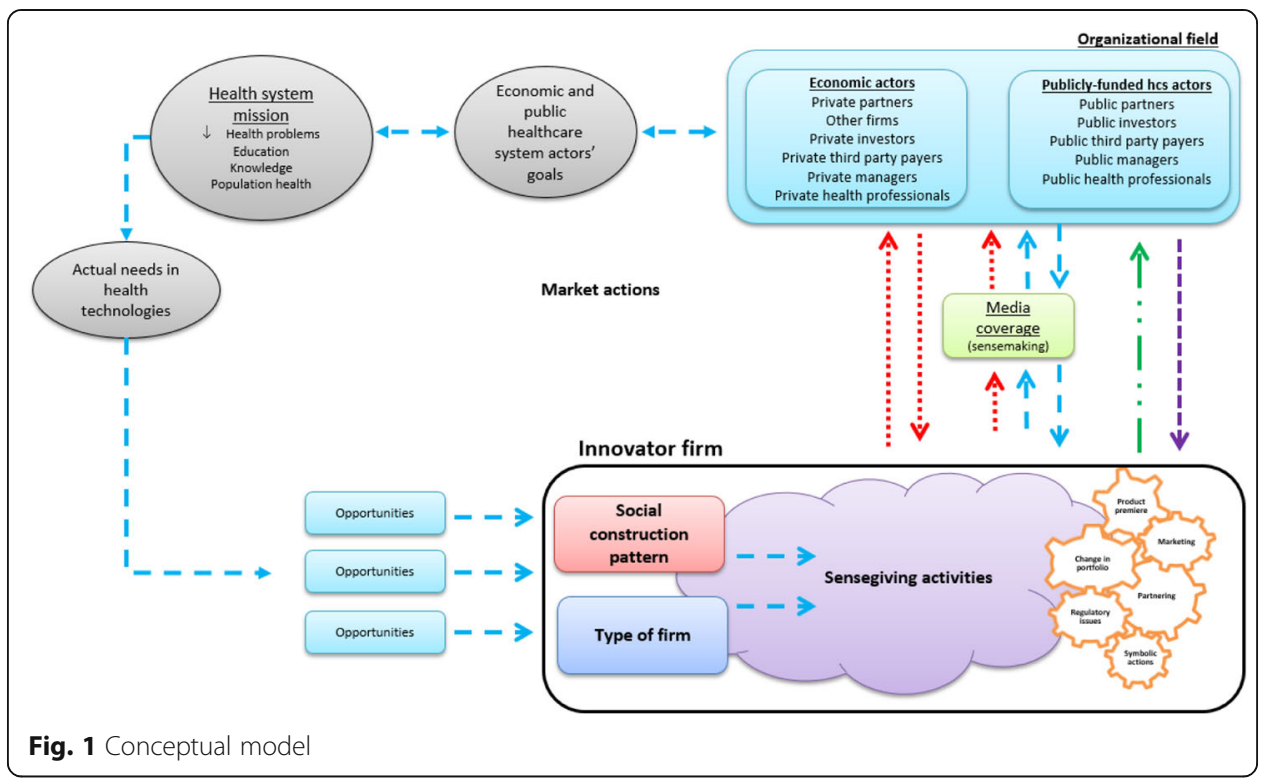

of legitimacy, status, and reputation-building and transforms its intentions into market actions. These sensegiving activities and competitive actions, labeled as institutional work, consist of strategic responses to pressures coming from the members of the organizational field that are economic players (private partners, other firms, private investors) as well as the public health actors (healthcare professionals, managers, and decision-makers). Finally, these actions aspire to enter the institution that is the health system and influence its financing, development, evaluation, acquisition, and diffusion. Thereby, firms interact with economic and public health actors to ultimately respond to health needs expressed by the health system (World Health Organization 2011a).

A coding framework was designed to get an overview of the collected data, and thematic analysis was then used to identify, analyze, and report patterns (themes) within data, while minimally organizing and describing the data set in detail (Braun and Clarke 2006). Guided by this approach, a second, thematic framework was developed by combining whatever it pertained to institutionalization of practices, isomorphism, and organizational field while staying vigilant for additional themes emerging from the interviews. Using the thematic framework, all the transcripts were then coded or re-coded. Such tagging and coding was done systematically through the entire data set, giving full and equal attention to each data item, and interesting aspects in the data items that may form the basis of new patterns across the data set were identified. Summaries of each coded passage were placed in Excel charts with links back to the paragraph number. Illustrative quotes were also highlighted. The charts enabled the researchers to look within and between cases and to identify outliers which did not fit with the majority view for a certain theme or sub-theme. The charts were used to describe, categorize, and interpret the data, grounded in the individual accounts. The final stage of data management involved sorting and synthesizing the original data and using the data categorized in the previous part to create a series of thematic charts. Analysis involved a constant moving back and forward between the entire data set and the coded extracts of data under analysis. 


\section{Appendix}

\section{Interview questionnaire}

How can innovative health firms satisfy economic and health system actors by socially constructing themselves in its organizational field?

\section{Preliminary questions}

1. What position do you hold in the organization?

2. What is your training (studies, specialties)?

3. How long have you worked for this organization?

4. What is your involvement in the evaluation or use of innovations in health?

5. In your opinion, what are the key issues affecting the financing, development, evaluation or use of innovations in health?

\section{Part 1-Market actions}

6. The companies that market new technologies attempt to directly or indirectly influence the choice of adoption of their product. Which of the following market actions do you think might influence you, and why? As an example, you receive information about competitive actions such as (see Table 6)

7. We have observed that over time communications with marketing content (e.g. deal announcements with hospitals or health groups) and symbolic actions (e.g. endorsement of a charity, prestigious nominations) increase while information content (e.g. new studies, applications) is impoverished. Can you comment on this observation and did you also observe this phenomenon?

8. Do you find that regulatory agencies (e.g., Health Canada) and / or professional associations (e.g. College of Physicians, American Heart Association) have too much to say in the process of adoption and diffusion of innovation?

9. Do you think that too many stakeholders (a lot of decision levels, physicians, third-party payers, managers, shareholders) are involved in the innovation diffusion process? Do you think some actors harm the process, the health system and/or the sustainability of innovation?

\section{Part 2-Disruptive innovations, startups and media coverage}

10. Do you have a different reaction to disruptive innovations (e.g. innovations which can be refocused and adapted to existing markets, or targeted for new markets, can these technologies change the rules of the market) compared to incremental innovations?

11. For example, in our research, a health innovation was considered "disruptive" because it consisted of risk management software for childbirth and was aimed at the market of obstetricians (who had never previously used such a tool).

a. Similarly, do you respond differently to emerging companies, compared with established companies with proven records? For example, can a good relationship with a representative or a good collaboration with the company influence your actions?

b. Are you influenced by media coverage of an innovation, whether by the journalist interpretation or the scale of media coverage? 
Table 6 Competitive actions

\begin{tabular}{ll}
\hline Competitive action & Examples \\
\hline Product premiere & Product launch \\
& Product introduction \\
& 1st patient/clinical use in human \\
& New product version \\
Change in portfolio/business model or structure & Portfolio sale/acquisition \\
& New commercial license \\
Partnering & New business/consolidation plan \\
& Partnerships/alliances \\
& Distribution agreement \\
Marketing & Collaborative initiatives \\
& Conference presentation \\
& Sales update \\
Regulatory issues & Commercial product update \\
& Clinical study update \\
Symbolic actions & Health and financial regulatory bodies approvals \\
& Patent updates (non-litigious) \\
& Awards \\
& Appointments \\
& Patents updates (litigious) \\
Voluntary recalls & Advisory board changes \\
New brand identity \\
Performance lists/indexes \\
Customer satisfaction scores
\end{tabular}

\section{Abbreviations}

BRIC: Brazil, Russia, India, and China; CHU: Centre hospitalier universitaire; CHUM: University of Montreal Health Centre; $\mathrm{HI}$ : Investment fund partners specialized in health innovations; HP: Health professionals; HT: Members of health technology assessment units; HTA: Health technology assessment; INESSS: Institut national d'excellence en santé et services sociaux; MD: Medical specialist

Funding

The publication fees were partially funded by the Institute of Public Health Research of University of Montreal (IRSPUM).

\section{Availability of data and materials}

Data supporting their findings can be provided on demand, including anonymized transcripts.

\section{Authors' contributions}

All authors have seen and approved the manuscript, and they have contributed significantly to the work.

\section{Competing interests}

The authors declare that they have no competing interests. I warrant that authors have no financial interest in the drugs, devices, or procedures described in the enclosed manuscript.

\section{Publisher's Note}

Springer Nature remains neutral with regard to jurisdictional claims in published maps and institutional affiliations.

Received: 29 March 2018 Accepted: 5 September 2018

Published online: 26 September 2018

\section{References}

Baker, D., \& Khamsi, R. (2012). Straight talk with...David Baker. Nature Medicine, 18(11), 1599. https://doi.org/10.1038/nm1112-1599.

Barnett, J., Vasileiou, K., Djemil, F., Brooks, L., \& Young, T. (2011). Understanding innovators' experiences of barriers and facilitators in implementation and diffusion of healthcare service innovations: a qualitative study. BMC Health Services Research, 11(1), 342. https://doi.org/10.1186/1472-6963-11-342.

Basdeo, D. K., Smith, K. G., Grimm, C. M., Rindova, V. P., \& Derfus, P. J. (2006). The impact of market actions on firm reputation. Strategic Management Journal, 27(12), 1205-1219. https://doi.org/10.1002/smj.556.

Beaulieu M, Lehoux P. (2017). The emergence of health technology firms through their sensegiving activities and competitive actions. International Journal of Innovation Management, 21(6), 1750043. https://doi.org/10.1142/S1363919617500438.

Bergsland, J., Elle, O. J., \& Fosse, E. (2014). Barriers to medical device innovation. Medical Devices (Auckland), 7, 205-209. https://doi.org/10.2147/MDER.S43369. 
Braun, V., \& Clarke, V. (2006). Using thematic analysis in psychology. Qualitative Research in Psychology, 3(2), 77-101.

Canadian Agency for Drugs and Technologies in Health. (2006). Guidelines for the economic evaluation of health technologies (3rd ed.) Retrieved from Ottawa: http://www.cadth.ca/media/pdf/186_EconomicGuidelines_e.pdf.

Chilcott, J., Tappenden, P., Rawdin, A., Johnson, M., Kaltenthaler, E., Paisley, S., et al. (2010). Avoiding and identifying errors in health technology assessment models: qualitative study and methodological review. Health Technololgy Assessment, 14(25), iii-iv, ix-xii, 1-107. https://doi.org/10.3310/hta14250.

Dimaggio, P., \& Powell, W. W. (1983). The iron cage revisited: institutional isomorphism and collective rationality in organizational fields. American Sociological Review, 48(2), 147-160. https://doi.org/10.2307/2095101.

Donabedian, A. (1973). The assessment of need. In Aspects of medical care administration: Specifying requirements for health care (pp. 58-69). Cambridge: Harvard University Press.

Ferrier, W. J., Smith, K. G., \& Grimm, C. M. (1999). The role of competitive action in market share erosion and industry dethronement: a study of industry leaders and challengers. Academy of Management Journal, 42(4), 372-388. https://doi. org/10.2307/257009.

Fligstein, N. (2001). Social skill and the theory of fields. Sociological Theory, 19(2), 105-125. https://doi.org/10.1111/0735-2751.00132.

Flyvberg, B. (2006). Five misunderstandings about case-study research. Qualitative Inquiry, 12(2), 219-245.

Gagnon, M. P. (2014). Hospital-based health technology assessment: developments to date. Pharmacoeconomics, 32(9), $819-$ 824. https://doi.org/10.1007/s40273-014-0185-3.

Galletta, A. (2013). Mastering the semi-structured interview and beyond. New York: New York University Press.

Galvin, T. L. (2002). Examining institutional change: Evidence from the founding dynamics of US health care interest associations. Academy of Management Journal, 45(4), 673-696. https://doi.org/10.2307/3069304.

Glaser, B. G., \& Strauss, A. L. (1967). The discovery of grounded theory. New Brunswick: Aldine Transaction.

Greenwood, R., \& Suddaby, R. (2006). Institutional entrepreneurship in mature fields: the big five accounting firms. Academy of Management Journal, 49(1), 27-48.

Greenwood, R., Suddaby, R., \& Hinings, C. R. (2002). Theorizing change: the role of professional associations in the transformation of institutionalized fields. Academy of Management Journal, 45(1), 58-80. https://doi.org/10.2307/3069285.

Grutters, J. P., Seferina, S. C., Tjan-Heijnen, V. C., van Kampen, R. J., Goettsch, W. G., \& Joore, M. A. (2011). Bridging trial and decision: a checklist to frame health technology assessments for resource allocation decisions. Value in Health, 14(5), 777784. https://doi.org/10.1016/j.jval.2011.01.005.

Hallet, T., \& Ventresca, M. (2006). How institutions form: Loose coupling as mechanism in Gouldner's patterns of industrial bureaucracy. American Behavioral Scientist, 49, 908-924.

Havighurst, C. C. (2008). Disruptive innovation: the demand side. Health Affairs (Millwood), 27(5), 1341-1344. https://doi.org/10 1377/hlthaff.27.5.1341.

Hines, J. Z., Lurie, P., Yu, E., \& Wolfe, S. (2010). Left to their own devices: breakdowns in United States medical device premarket review. PLoS Medicine, 7(7), e1000280. https://doi.org/10.1371/journal.pmed.1000280.

Hoffman, A. J. (2001). Linking organizational and field-level analyses: the diffusion of corporate environmental practice. Organization \& Environment, 14, 133-156.

Innovation Science and Economic Development Canada. (2017, 2017-06-08). Industry profile. Life Science Industry. Retrieved from https://www.ic.gc.ca/eic/site/lsg-pdsv.nsf/eng/h_hn01736.html. Accessed 10 Jan 2018.

International Trade Administration. (2016). Top markets report medical devices. Retrieved from http://trade.gov/topmarkets/ pdf/Medical_Devices_Executive_Summary.pdf. Accessed 10 Jan 2018.

Jepperson, R. L. (1991). Institutions, institutional effects, and institutionalism. In W. W. Powell \& P. DiMaggio (Eds.), The new institutionalism in organizational analysis (pp. 143-163). Chicago: The University of Chicago Press.

Kerger, B. D., Bernal, A., Paustenbach, D. J., \& Huntley-Fenner, G. (2016). Halo and spillover effect illustrations for selected beneficial medical devices and drugs. BMC Public Health, 16, 979. https://doi.org/10.1186/s12889-016-3595-7.

Kitchener, M. (2002). Mobilizing the logic of managerialism in professional fields: the case of academic health centre mergers. Organization Studies, 23, 391-420.

Kuran, T., \& Sunstein, C. (1999). Availability cascades and risk regulation. Stanford Law Review, 51, 683-768.

Kvale, S. (2007). Doing interviews. Londres: SAGE Publications.

Lawrence, T., \& Suddaby, R. (2006). Institutions and institutional work. In S. R. Clegg, C. Hardy, T. B. Lawrence, \& W. R. Nord (Eds.), The SAGE handbook of organization studies (2nd ed., pp. 215-254). London: SAGE Publications.

Lehoux, P., Denis, J. L., Tailliez, S., \& Hivon, M. (2005). Dissemination of health technology assessments: identifying the visions guiding an evolving policy innovation in Canada. Journal of Health Politics, Policy and Law, 30(4), 603-641.

Martino, O. I., Ward, D. J., Packer, C., Simpson, S., \& Stevens, A. (2012). Innovation and the burden of disease: retrospective observational study of new and emerging health technologies reported by the EuroScan network from 2000 to 2009. Value in Health, 15(2), 376-380. https://doi.org/10.1016/j.jval.2011.11.034.

McCarthy, J. D., \& Mayer, N. Z. (1977). Resource mobilization and social movements: a partial theory. American Journal of Sociology, 82, 1212-1240

Meyer, J. W., \& Rowan, B. (1977). Institutionalized organisations: formal structure as myth and ceremony. American Journal of Sociology, 83(2), 340-363. https://doi.org/10.1086/226550.

Oliver, A., \& Sorenson, C. (2009). The limits and challenges to the economic evaluation of health technologies. In J. CostaFont, C. Courbage, \& A. McGuire (Eds.), The economics of new health technologies: incentives, organization, and financing. Oxford: Oxford University Press.

Oliver, C. (1991). Strategic responses to institutional processes. Academy of Management Review, 16(1), 145-179. https://doi. org/10.2307/258610

Oortwijn, W., \& Van der Wilt, G. J. (2016). Challenges in contemporary health technology assessment: a view from the outside. International Journal of Technology Assessment in Health Care, 32(1-2), 1-2. https://doi.org/10.1017/S0266462316000143.

Petkova, A. P., Rindova, V. P., \& Gupta, A. (2013). No news is bad news: sensegiving activities, media attention, and venture capital funding of new technology organizations. Organization Science, 24(3), 865-888.

Richter, J. (2004). Public-private partnerships for health: a trend with no alternatives? Development, 47(2), 43-48.

Rindova, V. P., Williamson, I. O., Petkova, A. P., \& Sever, J. M. (2005). Being good or being known: an empirical examination of the dimensions, antecedents, and consequences of organizational reputation. Academy of Management Journal, 48(6), 1033-1049. 
Schulman, K. A., Vidal, A. V., \& Ackerly, D. C. (2009). Personalized medicine and disruptive innovation: implications for technology assessment. Genetics in Medicine, 11(8), 577-581. https://doi.org/10.1097/GIM.0b013e3181ae0935.

Scott, W. R. (2001). Institutions and organizations. Thousand Oaks: Sage Publications.

Steinman, M. A., \& Baron, R. B. (2007). Is continuing medical education a drug-promotion tool?: YES. Canadian Family Physician, 53(10), 1650-1657.

Suchman, M. C. (1995). Managing legitimacy: strategic and institutional approaches. Academy of Management Review, 20(3), 571-610. https://doi.org/10.2307/258788.

Wooten, M., \& Hoffman, A. J. (2008). Organizational fields: past, present, and future. In R. Greenwood, C. Oliver, R. Suddaby, \& K. Sahlin (Eds.), The SAGE handbook of organizational institutionalism (p. 130). Londres: SAGE Publications.

World Health Organization. (2011a). Development of medical device policies. Retrieved from Geneva: http://whqlibdoc.who.int/ publications/2010/9789241564045_eng.pdf.

World Health Organization. (2011b, 9-11 September 2010). First WHO global forum on medical devices: Context, outcomes, and future actions. Paper presented at the First WHO Global Forum on Medical Devices, Bangkok, Thaillande.

Yin, R. (2014). Case study research. Design and methods (5th ed.). London: SAGE Publications.

Zipkin, D. A., \& Steinman, M. A. (2005). Interactions between pharmaceutical representatives and doctors in training: a thematic review. Journal of General Internal Medicine, 20(8), 777-786. https://doi.org/10.1111/j.1525-1497.2005.0134.x

Submit your manuscript to a SpringerOpen ${ }^{\circ}$ journal and benefit from:

- Convenient online submission

- Rigorous peer review

- Open access: articles freely available online

- High visibility within the field

- Retaining the copyright to your article

Submit your next manuscript at $>$ springeropen.com 